\title{
DA CATEGORIZACCÃO A MODELOS CULTURAIS: O GIRO SOCIAL (CULTURAL) EM LINGUÍSTICA COGNITIVA
}

\author{
From Categorization to Cultural Models:The De la categorización a modelos culturales: el \\ Social (Cultural) Turn in Cognitive Linguistics giro social (cultural) en lingüística cognitiva
}

Heloísa Pedroso de Moraes Feltes*

Universidade de Caxias do Sul, Centro de Humanidades, Caxias do Sul, RS, Brasil

\begin{abstract}
Resumo: Este ensaio discute noções em Linguística Cognitiva (LC) que implicam (re)avaliar compromissos ontológicos quando modelos teóricos se voltam a diferentes campos de aplicação. Por isso, retoma os conceitos de categorização, conceptualização, cognição corpórea, cognição situada, grounding (corpóreo, experiencial, sociocultural, interacional, discursivo), modelos cognitivos e culturais. A partir da problematização das noções de cognição/conceptualização situada e de grounding, ilustra casos de análises linguísticas em que termos, tais como: 'modelos cognitivos' e 'modelos culturais' são utilizados intercambiavelmente ou sem a devida definição, ou ainda sem o estabelecimento das distinções pertinentes. Demonstra, portanto, que a discussão sobre grounding no Social Turn em LC é fundamental para as distinções entre esses dois constructos teóricos, pois implica, em última instância, ressituar-se a noção de corporalidade na LC contemporânea e em seus acarretamentos teórico-ontológicos e teóricometodológicos.
\end{abstract}

Palavras-chave: Giro Social. Linguística Cognitiva. Grounding. Modelos culturais.

\begin{abstract}
A set of notions in Cognitive Linguistics (CL), which imply to (re-)evaluate ontological commitments, are discussed when theoretical models turn to different fields of application. Theoretically, the paper revisits sayings abaout categorization, conceptualization, embodied cognition, situated cognition, grounding (embodied, experiential, sociocultural, interactional, and discursive), cognitive and cultural models are revisited. Starting from issues surrounding the basic notions of cognition/situated conceptualization and grounding, we enlighten cases of linguistic analyses, where terms, such as cognitive models and cultural models, are employed interchangeably, improperly defined or without an establishment of pertinent distinctions. Therefore, the discussion about grounding in the Social Turn in CL reveals that it is paramount to create the proper distinctions between these two theories, because it implies, ultimately, resituating the notion of embodiment within the contemporary CL and its theoretical-ontological, theoretical-methodological entailments.
\end{abstract}

Keywords: Social Turn. Cognitive Linguistics. Grounding. Cultural models.

Resumen: Este ensayo discute nociones en Lingüística Cognitiva (LC) que implican (re) evaluar los compromisos ontológicos cuando los modelos teóricos recurren a diferentes campos de aplicación. Para ello, retoma los conceptos de categorización, conceptualización, cognición corporal, cognición situada, fundamentación (corpórea, experiencial, sociocultural, interaccional, discursiva), cognitiva y cultural. Desde la problematización de las nociones de cognición/conceptualización situada y de fundamentación, ilustra casos de análisis lingüísticos en los que términos como: 'modelos cognitivos' y 'modelos culturales' son utilizados indistintamente o sin la definición adecuada, o aún sin establecer las distinciones pertinentes.

* Doutora em Letras - Linguística Aplicada pela Pontifícia Universidade Católica do Rio Grande do Sul. Professora do Programa em Letras e Cultura da UCS. ORCID: https://orcid.org/0000-0002-2875-8660. E-mail: helocogn@terra.com.br. 
Demuestra, por lo tanto, que la discusión sobre fundamentación en el giro social en LC es fundamental para las distinciones entre estas dos construcciones teóricas, ya que implica, en última instancia, restablecer la noción de corporalidad en LC contemporánea y sus implicaciones teórico-ontológicas y teóricometodológicas.

Palabras clave: Giro social. Lingüística Cognitiva. Fundamentación. Modelos culturales.

\section{INTRODUÇÃO}

A guinada (o giro) sociocultural em Linguística Cognitiva (cf. HARDER, 2010) passou a dar atenção à variação, levando a uma aproximação com autores da Antropologia Cognitiva (e.g. KÖVECSES, 2005) e à criação de subáreas como a Sociolinguística Cognitiva (e.g, KRISTIANSEM; DRIVEN, 2008) e a Etnolinguística Cognitiva (e.g., BARTMIŃSKI, 2009), ambas tratando de categorização e variação sociocultural de diferentes modos. A Linguística Cognitiva se consolida como uma ciência da língua em uso, e alguns de seus desdobramentos avançam mais fortemente para o significado social, que prefiro considerar sociocultural. Nesses movimentos, adentramos mais profundamente nas ancoragens sociais (e culturais) dos processos de categorização e conceptualização, o que nos leva, ato contínuo, a rever, ampliar e conciliar a ontologia com as quais nos comprometemos, no período seminal da Linguística Cognitiva, com as novas perspectivas de estudo que são abraçadas na ampliação das relações interdisciplinares. Neste ensaio, todavia, não temos espaço para discutir uma série dessas consequências e, em vários momentos, há alguns saltos e algumas lacunas, entre as quais a principal é a própria concepção de discurso em Linguística Cognitiva.

Com isso em mente, o objetivo deste ensaio, além de provocar reflexões em algumas direções, é reforçar a relevância causal bidirecional entre modelos culturais e processos de categorização, principalmente de categorizações que envolvem um nível mais alto de abstração. O modo como ordinariamente pensamos, como seres sociais vivendo numa dada cultura, não se pauta essencialmente pelo uso de expressões cujo sentido advém do aprendizado de definições de experts. Construímos significados à medida que experienciamos, que interagimos com o mundo, por meio do corpo que temos e, dessa forma, criamos "teorias populares" que dependem de fatores individuais, ambientais, sociais, culturais, históricos, políticos, etc.

\section{ABORDAGENS SOBRE COGNIÇÃO CORPÓREA/CORPORIFICADA E GROUNDING}

Para chegarmos a uma discussão sobre modelos culturais e processos de categorização, destaco outras abordagens que têm (com maior ou menor força) influência em estudos em Linguística Cognitiva e que nos ajudam a entender o que significa cognição corpórea/corporificada, cognição situada e grounding. ${ }^{1}$

\footnotetext{
${ }^{1}$ Não traduzimos o termo 'grounding', pois, como uma forma nominal, não se ajusta a vários contextos de tradução em Língua Portuguesa. Formas verbais do verbo 'to ground' são traduzidas como 'fundar', 'embasar'.
} 
A categorização é o coração da Linguística Cognitiva e um dos fenômenos centrais, por exemplo, nas várias disciplinas que constituem a Ciências Cognitivas em geral. Portanto, são múltiplas as áreas que abordam esse fenômeno. Conforme Lakoff (1987, p. 5-6, grifos nossos),

\begin{abstract}
Não há nada mais básico do que a categorização para nosso pensamento, percepção, ação e fala. Toda vez que vemos algo como um tipo de coisa, uma árvore, por exemplo, estamos categorizando. Sempre que raciocinamos sobre tipos de coisas: cabelos, nações, doenças, emoções e tudo o mais estamos empregando categorias. [...] E cada vez que produzimos ou entendemos qualquer enunciado de qualquer extensão, estamos empregando dezenas ou centenas de categorias: categorias de sons da fala, de palavras, de frases ou orações, bem como categorias conceptuais. Sem a habilidade de categorizar podemos não funcionar completamente no mundo físico ou em nossas vidas sociais ou intelectuais. Um entendimento de como categorizamos é central para qualquer entendimento de como pensamos e como funcionamos e, portanto, central para o entendimento do que nos faz humanos. [...] Uma grande proporção de nossas categorias não são categorias de coisas; elas são categorias de entidades abstratas [...], ações, emoções, relações espaciais, relações sociais, [...]. Qualquer abordagem adequada do pensamento humano deve prover uma teoria acurada para todas nossas categorias, tanto concretas como abstratas.
\end{abstract}

Em Linguística Cognitiva, há distinções entre conceito e categoria de acordo com os modelos teóricos propostos (cf. e.g., CROFT; CRUSE, 2004; TAYLOR, 2003; GEERAERTS; CUYCKENS, 2007), e o mesmo ocorre com modelos teóricos em Ciências Cognitivas (cf., e.g., COHEN; LEFEBVRE, 2005).

Mesmo concebidos como processos distintos, categorização e conceptualização estão interligados entre si, assim como com outros processos e entidades teóricas. Por exemplo, é proposto que a categorização é o processo pelo qual conceitos, como mecanismos de reconhecimento de padrões, determinam se uma entidade é ou não membro de uma categoria. Pode-se dizer que uma das funções conceptuais é a categorização. Ao se classificar algo como membro de uma categoria, pode-se utilizar esse conhecimento para classificar novas entidades e utilizar o conhecimento relevante para compreensão, inferências e predição (SMITH; MEDIN, 1981).

Lakoff (1987, p. 286) afirma que a capacidade de conceptualização é central na abordagem experiencialista, porque os conceitos são elementos de modelos cognitivos. Para cada conceito haveria uma categoria correspondente: entidades em um dado domínio do discurso com o qual o conceito, como caracterizado pelo modelo cognitivo, se ajusta. Os conceitos podem ser caracterizados por um modelo de categorização por condições necessárias e suficientes (modelo clássico); por efeitos de prototipicidade metonímica (modelo metonímico pelo mapeamento da parte da categoria para o todo da categoria); e por uma escala de gradação pelo modelo de categoria graduada.

Um exemplo dessas relações entre conceptualização e categorização encontramse em Kövecses (2005), quando o autor trata de TIME (TEMPO):

\footnotetext{
Pessoas em muitas culturas conceptualizam o tempo como algo estático e como algo dinâmico. A conceptualização do tempo muitas vezes envolve a categorização do tempo em passado, presente e futuro. E quando pensamos o tempo em termos dinâmicos, concebemolo como "passando", isto é, falamos como passagem do tempo. Ambas as conceptualizações são inevitável e inerentemente metafóricas. (p. 47, grifos nossos)
} 
Uma abordagem, em Psicologia Cognitiva Experimental, que escolho mencionar é a de significado situado ou conceptualização situada de Barsalou (2005, p.622), segundo a qual "[e]m vez de serem descontextualizadas e estáveis, as representações conceptuais são dinamicamente contextualizadas de modo a dar conta de diversos processos para alcançar objetivos" (p. 622). Comparando sua Teoria da Simulação Situada com outras teorias sobre sistemas conceptuais, Barsalou (2003) afirma que

\begin{abstract}
Um sistema conceptual contém conhecimento sobre o mundo. Uma propriedade fundamental desse conhecimento é sua natureza categorial. Um sistema conceptual não é uma coleção de imagens holísticas do tipo que uma câmera, gravador de vídeo ou gravador de áudio captura. Em vez disso, um sistema conceptual é uma coleção de conhecimento de categorias, em que cada categoria representada corresponde a um componente da experiência - não de uma experiência holística inteira. (p. 513-514, grifos do autor)
\end{abstract}

Barsalou entende que um conceito é como um manual de instrução dependente de um agente que libera pacotes especializados de inferências para guiar interações do agente com membros de uma categoria particular em situações específicas, de acordo com seus objetivos e restrições. Conceptualização situada é um pacote particular de inferências específicas para uma situação. Em outras palavras,

\begin{abstract}
voltando-se para a abstração e a estabilidade, a visão da simulação situada defende de que as representações conceptuais são contextualizadas e dinâmicas. Um conceito não é uma representação singular abstraída para uma categoria, mas, sim, uma habilidade para construir representações idiossincráticas atreladas às necessidades correntes de uma ação situada. (BARSALOU, 2003, p. 521)
\end{abstract}

Em publicação posterior Barsalou (2005), considera que em termos neurais, o estabelecimento de uma representação multimodal de uma categoria num sistema distribuído é denominado 'simulador'. Um simulador funciona como um type que integra o conteúdo multimodal de uma categoria. Quando estabelecido para uma categoria, o simulador reencena um subconjunto pequeno de seu conteúdo como simulações específicas, ou seja, apenas um pequeno subconjunto é ativado para representar a categoria numa ocasião especial. Ainda segundo Barsalou (2005), um número infinito de simuladores podem ser desenvolvidos na memória, cobrindo todas as formas de conhecimento (e.g., objetos, propriedades, eventos, ações, cenários, introspecções). O autor afirma que o sistema cognitivo é flexível, adquirindo novas propriedades que se revelam importantes para dada categorização. Porém, para ele, a questão chave é por que a atenção focaliza alguns componentes e não outros, de modo a criar simuladores para tais componentes. A resposta envolve o fato de que muitos fatores influenciam o processo, tais como: a genética, o desenvolvimento da linguagem, a cultura e objetivos a serem alcançados.

Barsalou (2010, p. 718) sinaliza que entre os diferentes campos científicos que tratam de conceptualização, a Psicologia Cognitiva oferece achados que indicam que "variáveis sensório-motoras afetam diversas tarefas associadas com percepção, ação, memória, conhecimento, linguagem e pensamento, implicando, do início ao fim, os sistemas modais do cérebro na cognição". O autor explica que, para alguns pesquisadores, 'grounded cognition' é equivalente à 'embodied cognition', o que ele considera um equívoco. Barsalou (2010, p. 721, nota 2) explica que: 
Embora algumas dessas pesquisas impliquem o corpo como um mecanismo importante de grounding, outras pesquisas implicam também as modalidades, o ambiente físico e o ambiente social como importantes mecanismos de grounding. Portanto, referir como cognição "corporificada" todas essas pesquisas deixa de capturar o amplo escopo dos mecanismos de grounding, ao mesmo tempo que simultaneamente dá a impressão equivocada de que estados corpóreos sempre determinam o curso da cognição. " Grounded cognition" captura o amplo escopo de mecanismos de grounding, dado que não coloca uma ênfase indevida sobre o corpo.

Para Barsalou (2010), a conceptualização é multimodal, e o conhecimento é embasado num sistema composicional de símbolos perceptuais. As representações internas são completadas à medida que o sistema cognitivo utiliza o ambiente e o corpo como estruturas de informações externas. É assim que as representações internas são situadas, com sua implementação realizada por simulações nos sistemas modais do cérebro, as quais ajustam-se para criar uma interface com estruturas. ${ }^{2}$

Para Barsalou (2005, p. 627):

\begin{abstract}
Uma conceptualização situada tipicamente simula quatro tipos básicos de componentes: (1) percepções de pessoas e objetos relevantes, (2) ações de um agente e outros estados corpóreos, (3) estados introspectivos, tais como emoções e operações cognitivas, e (4) cenários prováveis. Colocando tudo isso junto, a conceptualização situada é uma simulação multimodal de uma situação multicomponencial, com cada componente de modalidade específica simulado numa respectiva área do cérebro.
\end{abstract}

O autor ressalta que um simulador sozinho não produz uma conceptualização situada. É necessária a contribuição de muitos simuladores para a coleção de componentes que uma conceptualização situada contém.

Barsalou (2005, p. 628) defende que as conceptualizações situadas representam o conhecimento "impregnado" (entrenched) de situações repetidamente vividas por uma pessoa. O conhecimento multimodal acumula conhecimentos de pessoas, objetos, ações, introspecções e cenários relevantes num dado simulador. Os componentes "entranham" nos respectivos simuladores, assim como as associações entre esses componentes. Como consequência, quando uma conceptualização se torna bem-estabelecida, ela automática e imediatamente vem à mente como uma unidade no momento em que a situação (repetida) surge. As conceptualizações situadas impregnadas resultam de um padrão chamado "processo de acabamento inferencial": nem toda a situação é percebida de início, quando uma conceptualização situada entranhada é ativada por uma situação específica. Pode-se perceber uma pessoa, um cenário ou um evento relevante e, então, em uma situação particular que está prestes a se desdobrar, estará no âmbito do interesse do agente antecipar ou não o que acontecerá em seguida. Nesse processo de acabamento, é o agente que deve derivar as inferências que irão além da informação dada, de modo que a conceptualização situada ativada seja uma fonte rica de inferências.

2 As controvérsias sobre representações amodais e modais geram debates e pesquisas empíricas que estudiosos da Cognição deveriam acompanhar. De acordo com Haimovici (2018, p. 13, grifos nossos), considerando o atual estágio desses debates, "[e]mbora a distinção entre representações modais e amodais esteja no centro de um dos principais debates sobre conceitos, os critérios disponíveis para a distinção são problemáticos. Sem um critério que ofereça uma distinção conceptual e empírica adequada, uma avaliação apropriada da evidência para cada tipo de formato não é possível”. 
A conceptualização é um padrão, uma configuração complexa de componentes multimodais que representam uma situação. Finalmente,

Quando uma situação vista parcialmente ativa uma conceptualização situada, a conceptualização completa o padrão que a situação sugere. À medida que a conceptualização situada impregna-se na memória, é provável que esse processo ocorra de forma relativamente automática. (BARSALOU, 2005, p. 628)

É natural que se aborde Cognição Situada sobre a qual se fala extensamente em Linguística Cognitiva, para distingui-la da Teoria da Conceptualização (ou Simulação) Situada proposta por Barsalou. Em Linguística Cognitiva, cognição situada é uma das denominações da cognição corpórea, um dos paradigmas das Ciências Cognitivas ou, como afirma Lakoff (1987), a perspectiva da segunda geração das Ciências Cognitivas. Entretanto, há diferentes abordagens de cognição corpórea (Cf. SHAPIRO, 2011). Interessam aqui aquelas que se relacionam com processos de categorização. $O$ primeiro ponto a se observar é o de que se deve ter cuidado ao empregar as expressões 'cognição situada' ou 'cognição corpórea' de acordo com diferentes abordagens ou uma mesma abordagem ao longo de seu desenvolvimento. Podemos dizer que a cognição corpórea/corporalizada é situada, ou seja, a cognição é fundamentada (grounded), no corpo, nas situações e nas interações com o ambiente na geração de sistemas cognitivos.

Uma dessas abordagens de cognição corpórea é liderada por Lakoff, Johnson e colaboradores. Lakoff (1987) e Lakoff e Johnson (1999), em linhas gerais, afirmam sobre a "mente corporificada" que (a) a estrutura conceptual origina-se de nossa experiência sensório-motora e das estruturas neurais que lhes dão origem, sendo a noção de "estrutura" caracterizada como esquemas de imagens e esquemas motores; (b) as estruturas mentais são intrinsecamente significativas devido à sua conexão com nossos corpos e nossa experiência corpórea, o que contraria a ideia de manipulação de símbolos não semantizados; (c) há um nível básico de conceitos que originam parte de nossos esquemas motores e nossas capacidades para percepção gestáltica e formação de imagens; (d) nossos cérebros são estruturados de forma a projetar a ativação de padrões de áreas sensório-motoras para níveis corticais mais altos, constituindo as chamadas metáforas primárias, e tais projeções permitem-nos conceptualizar conceitos abstratos com base em padrões inferenciais utilizados em processos sensório-motores que estão diretamente ligados ao corpo; (e) a estrutura dos conceitos inclui protótipos de vários tipos: casos típicos, casos ideais, estereótipos sociais, exemplares salientes, pontos de referência cognitivos, entre outros, de modo que cada tipo de protótipo utiliza uma forma distinta de raciocínio; (f) a razão é corpórea quando nossas formas fundamentais de inferência originam-se de formas sensório-motoras e outras formas de inferência baseadas na experiência corpórea; (g) a razão é imaginativa porque as formas de inferência são mapeadas de modos abstratos de inferência pela metáfora; e (h) os sistemas conceptuais são pluralísticos, não monolíticos, de tal sorte que conceitos abstratos são definidos por múltiplas metáforas conceptuais que são muitas vezes inconsistentes entre si. Em suma, a cognição corpórea está mais relacionada ao corpo e como o corpo interage com o "mundo". 
A distinção entre cognição corpórea e cognição situada não se aplica à abordagem de Gibbs (2006). O autor esclarece que a, antes de uma dotação biológica é uma categoria de análise sociocultural que revela dimensões complexas das interações entre corpos e personalidade (personhood). Nesse sentido, a questão da é situada com relação, por exemplo, "à saúde e à doença, parentesco, modos de produção e trocas, gênero, hierarquias etárias, práticas de linguagem, religião e disciplinas políticas, regras jurídicas, metáforas pervasivas, possessão espiritual, experiências históricas e mitos" (GIBBS, 2006, p. 37). O autor afirma que nossos corpos incorporam significados e memórias culturais. E, com base em outros autores, acrescenta que a experiência corporificada é, em si, culturalmente constituída, de modo que muitas experiências corporificadas são enraizadas em contextos socioculturais. Ou seja:

\footnotetext{
Corpos não são objetos isentos de cultura, porque todos aspectos da experiência corporificada são moldadas por processos culturais. Uma teoria sobre o sistema conceptual humano deveria ser inerentemente cultural, no sentido de que a cognição que ocorre quando o corpo encontra o mundo é, inextricavelmente, culturalmente baseada. (GIBBS, 2006 p. 13, grifos do autor)
}

Neste ponto, podemos tratar do que se entende por grounding (que diz respeito, em termos suficientemente compreensíveis, à ancoragem do significado ou em que, por exemplo, a categorização ou conceptualização está baseada, fundada). Harder (2010, p. 21) defende que "grounding envolve motivação, não fundamentacionalismo dogmático"

De acordo com Harder (2010, p. 79, grifos nossos):

\begin{abstract}
Grounding é a diferença chave fundamental entre a primeira geração de ciências cognitivas e LC [Linguística Cognitiva]. A plataforma da LC foi e é a de que a linguagem e o significado não são autônomos e entidades autocontidas, mas fundadas na cognição humana como um todo, que é, por sua vez, fundada no corpo humano como um todo.[...] A fim de acomodar a dimensão social nesse quadro, essa noção de grounding não é mais suficiente.
\end{abstract}

O autor sustenta que, num primeiro estágio da Linguística Cognitiva, a corporificação (embodiment) significava centralmente grounding no corpóreo (bodily grounding). Quando se trata de relacionar um objeto de descrição focal, o grounding envolve o contexto em que o objeto focal se inscreve. Entretanto, a partir do giro social da linguística Cognitiva, além da centralidade de bodily grounding, inclui-se a ancoragem do significado no feedback a partir do ambiente; portanto, fora do corpo do indivíduo: o experiencial grounding. Nesses termos, as pessoas, em suas experiências diárias, lidam com diferentes taxonomias e há outros fatores a serem considerados "para entender o tipo de representação mental que pessoas reais constroem" (HARDER, 2010, p. 20).

Para Harder, o grounding corpóreo já não basta para examinar os processos de conceptualização que são afetados pela cultura, porque apenas com grounding corpóreo a "cultura seria reduzida à cognição e a cognição à atividade neural" (HARDER, 2010, p. 176). Portanto, deve-se ter em conta o grounding corpóreo (dentro do indivíduo) e grounding sociocultural. Em outras palavras: 
Conceptualização e linguagem são fundadas na experiência corpórea (dentro do indivíduo) e em participação na comunidade (fora do indivíduo). Se o grounding corpóreo estivesse sozinho na cena, não poderíamos ter palavras ou conceitos para coisas das quais não tivemos experiências pessoais; se grounding sociocultural operasse sozinho, sem o grounding corpóreo, falaríamos sempre sobre cores como um homem cego. (HARDER, 2010, p. 446, grifos nossos)

Sinha (1999), embora se distancie de grande parte dos pesquisadores no campo da Linguística Cognitiva por defender um realismo referencial, entende que discutir a natureza do grounding é fundamental, porque, para ele, "a conceptualização é a organização de uma situação referencial em um universo de discurso compartilhado intersubjetivamente" (p. 230).

$\mathrm{O}$ autor defende um realismo referencial porque entende que em semântica cognitiva não é possível rejeitar o Objetivismo e o Subjetivismo (cf. LAKOFF, 1987) sem que haja uma teoria do significado que identifique o significado com conceptualização, mantendo indeterminada a relação com o mundo. Sinha (1999, p. 232, grifos do autor) visa oferecer uma abordagem de cognição e semântica que é "discursivamente mais situada, dependente de contexto [..] em que processos mentais de conceptualização, esquematização e perspectivização formam a base psicológica de atos discursivos de falar e entender". Sobre o realismo referencial, o autor defende que

precisamos entender que a conceptualização linguística é um processo ativo que é, apropriadamente falando, parte da referência linguística. Conceptualizamos na linguagem, $a$ fim de referir a algo, numa situação, para alguém. O realismo referencial é baseado no entendimento do significado como agir comunicativamente em um mundo intersubjetivamente compartilhado ou universo do discurso. (SINHA, 1999, p. 234, grifos do autor)

A abordagem de Sinha (1999) envolve: (a) uma psicologia baseada no realismo ecológico, no qual há uma realidade independente da mente e há princípios de organização perceptual, atencional e motora; (b) o entendimento de que a conceptualização "depende de e é esquemática e figurativamente motivada por seu grounding corpóreo" (p. 246) no Umwelt (mundo vivido) ecológico, mas não é nem idêntico nem redutível a ele; (c) a defesa de que o grounding discursivo constitui a motivação funcional básica da construção linguística.

Essa base funcional provê "uma ponte comunicativa e cognitiva entre grounding corpóreo - o grounding da linguagem em esquematizações não discursivas e a própria conceptualização linguística" (SINHA, 1999, p. 247, grifos do autor).

O realismo referencial de Sinha defende que as conceptualizações linguísticas são atos particulares de significado linguístico, que a cognição linguística é a capacidade cognitiva dos sujeitos para produzir e entender atos de significado linguístico, e que conceptualizações linguísticas e cognição linguística são dependentes da língua, o meio simbólico de expressão linguística. Em suma:

\footnotetext{
No curso da aquisição da linguagem e tornando-se um membro da comunidade de fala a sua volta, a criança desenvolve a habilidade crescente de participar de atos de significados fundados em um universo de discurso constituído pela língua em si mesma. Nesse sentido, não é apenas o caso de que o significado funda toda a língua, é também o caso de que a língua, como os meios normativos impregnados cognitivamente para realizar coordenações complexas de referência em campos intersubjetivos constituídos simbolicamente, funda o significado. (SINHA, 1999, p. 248, grifos nossos)
} 
Apesar de Sinha (1999) afirmar que sua abordagem é muito similar à de Harder (1999), por ambos defenderem um grounding dual, há discordâncias ontológicas substanciais entre as duas abordagens. Harder (1999, p.218) defende, 10 anos antes de sua apreciação do giro sociocultural da Linguística Cognitiva, que os fatos sociais "como um nível ontológico específico, deveriam ser incluídos de forma mais específica na visão de mundo da linguística Cognitiva". O autor defende que a natureza dos modelos cognitivos é fundada tanto em neurobiologia como em padrões de interação. Além disso, defende que o grounding funcional-interativo não é externo ao entendimento da sintaxe, mas, sim, parte do seu mecanismo básico funcional de combinação hierárquica (i. e. dependência funcional e não dependência conceptual).

Harder (2010) defende que as duas formas de grounding devem ser pressupostas: sociocultural grounding como um termo para dar conta de que um modelo conceptual está entranhado na vida da comunidade; e factual grounding à medida que um modelo conceptual se mostre um mapa confiável ao lidar com a realidade. Sua posição é de que essa abordagem (concentrado no processo de categorização) contrasta, de forma equilibrada, "um construcionismo puramente social e um entendimento puramente cognitivista de modelos conceptuais" (2010, p. 404). O autor deixa claro que o que defende não é uma forma radical de construcionismo social, mas uma visão cognitiva social. Harder (2010, p. 346) reforça sua posição:

\begin{abstract}
Os conceitos provêm um potencial essencial para dissociar-se de uma determinação fundacional e agir sobre o mundo de formas alternativas [...].[E]ssa liberdade conceptual deve evitar se tornar um relativismo sócio-construcionista submerso, assim como usar o fundamentalismo ou interpretações muito literais de grounding. (2010, p. 346, grifo nosso)
\end{abstract}

Ou seja, Harder (2010, p. 462)) não apoia "um relativismo em que todas as posições são igualmente válidas desde que solidamente fundadas nas normas da comunidade". Como o autor deixa claro já no início de sua obra, a "corporeidade implica um comprometimento com uma forma de realismo biológico” (2020, p. 88) Porém,

\begin{abstract}
epigênese, intersubjetividade, ancoragem material e desenvolvimento cultural ocorrem [no] mundo compartilhado. Representações, processos e mapeamentos cognitivos dependem de objetos, pessoas e práticas com propriedades que não apenas colidem com a cognição mas constituem o contexto pressuposto por ela - e, portanto, devem ser incluídos em uma abordagem plena de grounding. (HARDER, 2010, p. 87-88, grifo nosso)
\end{abstract}

As questões que trazemos neste ensaio dizem respeito a fundamentos teóricos (e ontológicos) que nos permitam tratar do significado (categorizações, conceptualizações) sociocultural. O espaço dado ao ponto de vista de Harder $(1999,2010)$ significa que concordamos com uma visão mais robusta de grounding. Todavia, Harder (2010, p. 392) resume sua contribuição a

\footnotetext{
Adicionar à análise cognitiva de modelos culturais pervasivos [...] uma análise das dimensões não cognitivas da esfera social. [...] Com respeito ao ponto mais cognitivo do spectrum, a contribuição que posso oferecer é como fatos cognitivos e fatos sociais interagem. [...] É crucial para a teoria que defendo é uma relação funcional e pancrônica em que a mente individual é parte e um padrão que envolve adaptação às forças, fora na mente individual, no nível da comunidade.
} 
O "giro social” na Linguística Cognitiva, pode levar às mais variadas propostas que, inclusive, defendem uma análise pós-estruturalista do discurso em que o mecanismo analítico,

reflete o padrão de pensamento construcionista social: a realidade extradiscursiva está fora de vista; a mente humana é um meio passivo para o processo social; processos sociais mediados pela linguagem com sua bagagem de conteúdo representacional são os únicos atores na cena, e o analista [...] pode essencialmente escolher ou mesmo construir o objeto sobre o qual quer se focar. (HARDER, 2010, p. 122-123)

Reiteramos que, ao aceitarmos propostas que constituem o "giro social" em Linguística Cognitiva, precisamos (re)examinar os compromissos que assumimos teórica ou metateoricamente.

\section{COGNIÇÃO SITUADA E MODELOS CULTURAIS}

Temos trabalhado com o constructo modelos culturais, de um modo não intercambiável com o construto modelos cognitivos, muitas vezes utilizados em termos genéricos. (cf. FELTES, 2018a, b). O constructo modelos culturais, embora não discutidos em Harder (2010), parece-nos uma escolha sólida o suficiente para avançarmos no entendimento da variação nos processos de categorização e conceptualização relativamente a fatores socioculturais, mantendo-nos ainda comprometidos com $\mathrm{o}$ Realismo Experiencial.

Levando em conta a variação sociocultural nos sistemas conceptuais humanos, um dos pesquisadores em Linguística Cognitiva que tem introduzido o constructo 'modelos culturais' em suas pesquisas sobre metáforas e variação cultural é Kövecses (2005, p. 193). Para o autor:

\footnotetext{
Modelos culturais são importantes em nossas tentativas de descrever e caracterizar o sistema conceptual humano e, consequentemente, culturas. Psicólogos, antropólogos e linguistas têm usado extensivamente essa noção sob uma variedade de diferentes nomes [...] Modelos culturais são mais bem concebidos como quaisquer organizações da experiência humana compartilhada pelas pessoas.
}

O autor não menciona quais são as diferentes nomeações, remetendo o leitor para a obra de Holland e Quinn (1987) e de Lakoff (1987). Conforme Feltes (2007, 2018a), na obra organizada por Holland e Quinn, os autores, em geral, utilizam 'modelos culturais', definidos como 'esquemas compartilhados' ou como 'teoria popular'. Lakoff (1987) em nenhum momento utiliza 'modelos culturais', mas emprega "frames constituídos culturalmente' (p. 396) e 'cultural folk theory' (p. 398). Lakoff e Johnson (1999) utilizam a expressão "commonplace knowledge", que engloba "modelos culturais, folk theories, ou simplesmente "conhecimento ou crenças que são amplamente aceitas em uma cultura" (p. 60). 
Partindo de uma abordagem sobre a categorização pelo modelo de efeitos de prototipicidade, Ungerer e Schmid (2006) esclarecem que os protótipos de categorias cognitivas ou as fronteiras de uma categoria podem mudar de acordo com o contexto. Para os autores, "a estrutura interna global de uma categoria parece depender do contexto e, num sentido mais amplo, de nosso conhecimento social e cultural UNGERER; SCHMID, 2006, p. 48), os quais se organizam em modelos cognitivos e culturais.

Por essa razão, eles apresentam distinções entre termos utilizados no tratamento de conceitos e categorias: situação e contexto, bem como modelos cognitivos e modelos culturais. A situação é entendida como a interação entre objetos no mundo real. Por exemplo, no enunciado "The boy was building a sandcastle with his bucket and his spade" (UNGERER; SCHMID, 2006, p. 48), a situação ${ }^{3}$ é construída com quatro "objetos", um menino, um castelo de areia, um balde e uma espada, que interagem através da ação do menino. Quando o enunciado é processado pelo ouvinte ou leitor, as palavras evocam as categorias cognitivas correspondentes, ou de modo mais simples, o conceito mental que temos dos objetos no mundo real. Quando uma representação cognitiva da interação entre os conceitos é criada, forma-se, então, o contexto, que não permanece como uma experiência mental isolada, pois é imediatamente associada com o conhecimento estocado na memória de longo prazo e o conhecimento específico do contexto sobre as categorias envolvidas é recuperado. O contexto constrói a base de modelos cognitivos. (UNGERER; SCHMID, 2006).

Os modelos cognitivos de um domínio não possuem descrições exaustivas, são altamente seletivos e são inter-relacionados, ou seja, não são entidades cognitivas isoladas. Conforme os autores:

\begin{abstract}
Os modelos cognitivos são onipresentes. Em cada ato de categorização estamos mais ou menos conscientes relativamente a um ou vários modelos cognitivos que temos estocados. Apenas em casos muito raros quando encontramos um objeto ou situação com a qual não estamos completamente familiarizados nenhum modelo cognitivo estará disponível, mas mesmo assim, tentaremos evocar experiências similares e imediatamente formar um modelo cognitivo. (UNGERER; SCHMID, 2006, p. 51)
\end{abstract}

Modelos cognitivos representam uma visão cognitiva, psicológica, do conhecimento estocado sobre um certo campo e, dado que tais estados psicológicos são experiências individuais, as referidas descrições envolvem alto grau de idealização. No caso do exemplo fornecido pelos autores, as descrições nos modelos cognitivos baseiamse na suposição de que muitas pessoas têm, de forma muito grosseira o mesmo conhecimento sobre castelos de areia e praias. Entretanto, os modelos cognitivos não são universais, pois dependem da cultura em que a pessoa se desenvolve e vive. Desse modo, a cultura fornece o background para todas as situações que experienciamos para que formemos um modelo cognitivo. Portanto, os modelos cognitivos para domínios particulares dependem, em última instância, dos chamados modelos culturais, e estes podem ser vistos como modelos cognitivos que são compartilhados por pessoas que pertencem a um grupo ou subgrupo social. (UNGERER; SCHMID, 2006, p. 51). Para os

${ }^{3}$ Situações, ações e eventos também são categorizados. 
autores o uso do termo 'modelo cognitivo' "reforça a natureza psicológica dessas entidades cognitivas e permite diferenças inter-individuais, o termo 'modelo cultural' enfatiza o aspecto unificador de serem compartilhados por muitas pessoas" (p. 52). Em suma, os autores afirmam que

\begin{abstract}
Um número de distinções terminológicas parece necessário para uma visão diferenciada de categorias dependentes-de-contexto. Portanto, definimos situação como a interação de objetos no mundo real; contexto como a representação cognitiva da interação entre categorias cognitivas (ou conceitos); modelo cognitivo como a soma dos contextos experienciados e estocados por um indivíduo relativamente a certo campo; modelo cultural como uma visão de modelos cognitivos que realçam o fato de que são intersubjetivamente compartilhados pelos membros de uma sociedade ou grupo social. (UNGERER; SCHMID, 2006, p. 58, grifos nossos)
\end{abstract}

Kövecses (2004) estabelece a relação entre categorias linguísticas e modelos culturais afirmando que, de acordo com as pesquisas em Linguística Cognitiva, as categorias são, por natureza, polissêmicas, sendo que alguns membros de uma categoria são mais representativos, centrais ou prototípicos do que outros, não prototípicos. Segundo o autor (2004, p. 173):

\begin{abstract}
A polissemia natural das categorias linguísticas pode ser considerada como um grande conjunto de modelos culturais, com um ou alguns modelos no centro que servem como "pontos de referência cognitivos" para todos os outros modelos que desviam daqueles de algum modo.
\end{abstract}

Kövecses (2005) levanta uma importante questão: as metáforas refletem ou constituem modelos culturais? Não vamos detalhar a argumentação do autor sobre essa questão, pois ela nos serve apenas para realizar uma ponte com processos de categorização: modelos culturais atuam em processos de categorização? Que tipos de categorias são criadas pela ativação de modelos culturais?

No caso específico das emoções, Kövecses (2004) defende que metáforas constituem um modelo cultural, como o caso do modelo cultural de RAIVA, que é um cluster (i.e., não é monolítico) de várias metáforas (cf. FELTES, 2007; FELTES, 2018a), o que difere de antropólogos cognitivos que afirmam que a metáfora reflete modelos culturais pré-existentes. De qualquer modo, considerando que a variação cultural ocorre dentro da cultura e transculturalmente, alterando os modelos culturais prototípicos, o autor assinala que "dado um contexto cultural e sua influência na conceptualização, podese ver por que as mudanças acontecem nos modelos culturais e nas metáforas conceituais" (KÖVECSES, 2004, p. 181). Das análises de um conjunto de conceptualizações de emoções, Kövecses conclui que os modelos culturais podem ser esquemas de nível genérico (e.g. em emoções básicas, o esquema genérico seria causa-força-resposta), que parecem ser universais e esquemas culturais de nível específico, que dão conta da riqueza das experiências emocionais, "os quais parecem encapsular uma rica variedade de experiências determinadas culturalmente e que variam transculturalmente" (2004, p. 190). 
Yuanqiong (2009) questiona se as metáforas refletem ou constituem modelos culturais, ao analisar metáforas de TEMPO e de RAIVA na língua chinesa e na língua inglesa. Ela conclui que "as metáforas desempenham um papel indispensável na constituição de modelos culturais" (p. 124). Porém, entende que mesmo sendo uma parte importante na constituição da metáfora, os modelos culturais selecionam, dão forma e instanciam metáforas (a metáfora é considerada como filtro). Não há uma relação de dominação, "mas de promoção e restrição mútuas" (p. 132). Assim como modelos culturais podem atuar como filtros para metáforas, "novas metáforas têm o poder de criar novos modelos" (p. 132).

Os modelos culturais são esquemas molares socioculturalemente compartilhados, os quais são reconstruídos, orientados metodologicamente por procedimentos que partem da língua em uso e que são estruturados e estruturantes de processos de categorização. $O$ uso do termo 'modelos culturais', por conseguinte, não é intercambiável com o de 'modelos cognitivos'.

Segundo Lakoff (1987) há modelos cognitivos idealizados de diferentes tipos. Entre os modelos cognitivos proposicionais, ele inclui os frames. Ou seja, os frames seriam um tipo de modelo cognitivo, mas o autor não oferece uma definição de modelos culturais, conforme dissemos anteriormente.

\section{CONSTRUCTOS E METALINGUAGEM: ANÁLISES LINGUÍSTICAS}

Para ilustrar como o constructo modelos culturais tem sido utilizado em algumas análises ou discussões em Linguística Cognitiva, trazemos dois exemplos. Esses exemplos demonstram como o constructo é necessário não só na descrição de fenômenos linguísticos, mas em sua explicação.

Salomão (2009), no âmbito do projeto FrameNet, sobre o qual a autora trata no artigo, discute uma pergunta que Fillmore (1975) levanta: "É correto dizer que o Papa João XXIII morreu solteiro?” Salomão (2009, p. 172, grifos nossos) diz:

\footnotetext{
A conexão originária entre frame e modelo cultural é fácil de ser reconhecida. Para ficarmos no frame do CASAMENTO (na sua versão ocidental), é impossível ignorar sua relevância para definir ESTADOS CIVIS tais como os designados pelos lexemas companheira, concubina, viúva, separada (que, no Brasil, contrasta juridicamente com divorciada), ou para definir o que se entende por pensão alimentícia. Nesses casos, é bastante óbvio que $o$ "conhecimento do mundo" patrocina de forma organizada e previsível toda a atividade inferencial.
}

Salomão é bem precisa quanto ao imbricamento de categorias e conceitos, assim como a relação entre frames e modelos cognitivos. Para Fillmore (1982), o seu uso do termo 'frame' cobre, de modo geral, um conjunto de conceitos utilizados na literatura sobre a linguagem natural, tais como: "esquema", "script", cenário, aparato (scaffolding) ideacional, modelos cognitivos ou "folk theory" (p. 111). Para o autor, 
as palavras representam categorizações da experiência, e cada uma dessas categorias é baseada em uma situação motivadora que ocorre contra um background de conhecimento e experiência, Com respeito aos significados de palavras, a pesquisa em semântica de frame pode ser pensada como o esforço para entender qual o motivo que uma comunidade deveria ter encontrado para criar a categoria representada pela palavra e explicar o sentido da palavra ao apresentar e esclarecer esse motivo. (FILLMORE, 1982, p. 112, grifos nossos)

$\mathrm{O}$ autor, portanto, defende que ninguém pode realmente entender os significados das palavras sem entender as instituições sociais ou estruturas de experiências, padrões de práticas que elas pressupõem.

Salomão (2009), tomando o exemplo do frame CASAMENTO e, em relação a ele, o significado de 'bachelor', estruturado pelos traços [HOMEM, +ADULTO, +NÃO CASADO], com respeito à pergunta formulada por Fillmore (1975), assinala que o Papa obviamente cairia na classe de SOLTEIRO. Porém, considerando o modelo cultural SACERDÓCIO CATÓLICO, ao Papa não se aplicaria de forma sequer relevante tal conceito (SOLTEIRO) como um traço definitório. A autora complementa:

\begin{abstract}
O absurdo nas aplicações da definição de 'bachelor' resulta do fato de que os conceitos evocados por esse lexema são, na verdade, modelos culturais imbricados em outros modelos culturais: dizer que alguém é NÃO CASADO requer uma definição de CASAMENTO; de outro lado, para que o CASAMENTO como relação entre duas pessoas possa se estabelecer é necessário garantir a legitimidade da pré-condição de NOIVO; ora, quem assume ordens religiosas, dentro do modelo cultural do SACERDÓCIO CATÓLICO, está impedido de satisfazer essa pré-condição. Requer-se, então, para dar conta de todos os fatos, que a noção de significação lexical se torne internamente estruturada e complexa, de tal modo a motivar uma escala pragmática de aceitabilidade dos usos correntes: será talvez possível qualificar o Papa como bachelor, desde que se ressalve que o Papa não é um bachelor típico... (p. 172, grifos nossos)
\end{abstract}

O que desejo ressaltar por meio do artigo de Salomão é que o próprio texto permite, no processo de explicação, fazer a distinção entre frame e modelos culturais, mesmo que o artigo não trate de definir o que são modelos culturais (o que escapa ao objetivo do artigo, focado no desenvolvimento do projeto FrameNet-Brasil). Porém, muitos estudiosos não têm uma clara distinção entre o construto frame (para CASAMENTO) e o de modelo cultural (para SACERDÓCIO CATÓLICO).

No âmbito da Gramática das Construções, observa-se outra situação. Bronzato (2000, 2009), numa detalhada análise do processo de destransitivação de certos verbos, utiliza o constructo 'Modelos Cognitivos Idealizados (MCI)' ao tratar do enquadre da interdição na explicação de destransitivações verbais por omissão do tipo "Se a menina não quer dar $\varnothing$, por que vou forçar?' (BRONZATO, 2009, p. 81. Trecho retirado de um depoimento em uma obra sobre drogas). Essa construção agrega um significado que a autora refere como rompimento de regra de conduta. Segundo a autora, a ausência do NP-Complemento é uma "pista de acesso a um MCI de interdição" (p. 81). Considerando as discussões conceituais aqui desenvolvidas, do nosso ponto de vista, o mais apropriado seria utilizar a expressão "um modelo cultural de interdição" (tentando identificar o grupo social do sujeito que faz o depoimento, principalmente porque a autora mesma afirma que 
$\mathrm{Na}$ análise do fenômeno de destransitivação verbal, o papel das molduras comunicativas revelou-se muito mais decisivo na produção/interpretação do significado do que as teorias linguísticas pré-sociocognitivismo foram capazes de admitir. (BRONZATO, 2009, p. 95)

Bronzato (2010) utiliza as noções de esquema, frame, cenário, conceptualização, categorização modelos cognitivos e modelos culturais para tratar da metáfora SUCESSO É GUERRA. Trazer este texto para nossa discussão é uma forma de ilustrar o que parece ser muito comum em análises em Linguística Cognitiva: a intercambialidade entre termos. Vejamos alguns trechos:

\begin{abstract}
A partir de um sistema de implicações metafóricas e metonímicas, nosso modelo cultural licencia a metáfora estrutural SUCESSO É GUERRA [...] (BRONZATO, 2010, p. 120, grifos nossos)

[...] proporei um modelo cultural popular do conceito de SUCESSO que, associado às contribuições epistemológicas da $\mathrm{CGH}$, justifica a proposição da metáfora estrutural SUCESSO É GUERRA. (p. 121, grifos nossos) ${ }^{4}$

O uso, nessa Construção, de predicadores verbais semanticamente ligados ao frame de destruição parece refletir a conceptualização desses eventos sociais como arenas de guerra, iluminando uma estrutura radial metafórica que se ancora no modelo cognitivo da guerra (evento de destruição/ espetáculo prototípico) e irradia-se para os eventos sociais de entretenimento como a discussão, o jogo e a política, mapeando esses eventos como cenários de guerra. (p. 191-192, grifos nossos)

A vida é combate, e ter sucesso é ter força para destruir, vencendo, assim, os adversários concorrentes. Todo esse modelo cultural, forjado historicamente, está embutido na $\mathrm{CGH}$ que, fundada na metáfora, abre a janela da cognição, deixando-nos entrever as estruturas conceptuais e pré-conceptuais que a governam e, repetida no uso, permite a categorização e a convencionalização do padrão construcional. (p. 211, grifos nossos)
\end{abstract}

Damos ênfase aqui a apenas algumas expressões: "modelo cognitivo de guerra", "cenários de guerra", "frame da destruição", "modelo cultural forjado historicamente" [A vida é combate...]. Uma questão circunstanciada basta para entendermos a profusão de termos, qual seja: quando um modelo cognitivo, que pode ser, inclusive, um frame, passa a ser historicamente forjado por qual grupo social, sob que circunstâncias de interação? Embora seja compreensível o que é proposto nas descrições e explicações, é necessário distinguir 'modelos cognitivos idealizados' de 'modelos culturais'. Podemos, por outro lado, apenas pressupor que haja um modelo cultural de certo tipo relacionado a determinado fenômeno sem ter a reconstrução sistemática desse modelo cultural, porque, afinal, modelos culturais são ubíquos, estando relacionado à categorização, à conceptualização, a processos de compreensão e de geração de inferências.

Como discutimos em FELTES (2018a, 2018b), a reconstrução de modelos culturais é metodologicamente complexa. No caso da metáfora SUCESSO É GUERRA, é importante constituir um corpus de eventos de fala que permita identificar a moldura (framing) comunicativa e o grupo social (ou corpora, para diferentes grupos sociais). Também, conforme discussão anterior, é preciso analisar se tal metáfora reflete e/ou constitui um dado modelo cultural. Bronzato (2010, p. 120), ao afirmar "nosso modelo cultural licencia a metáfora [...]", não deixa claro se sendo a metáfora, de alguma forma, constituinte do modelo cultural, então ela é licenciada por ele, ou se a metáfora reflete (ou é causalmente resultado de) o modelo cultural.

\footnotetext{
4 'CGH' refere-se à Construção Gramatical de Hiperbolização.
} 
Veja o caso da pesquisa de Bortoni-Ricardo (1984, p. 19), que, ao analisar esforços de convergência em processos de comunicação entre acadêmicos e sujeitos analfabetos ou semi-analfabetos, de classe baixa e origem rural radicados em Brazlândia, cidadesatélite de Brasília, apresenta o seguinte caso (diálogo 9), baseado no tópico sucesso:

1. E: Depende de que o sucesso da gente? Pra gente conseguir alguma coisa, depende de quê? De quem?

2. MP (47 (32): Uai, depende da... da sistença da gente e da boa vontade, né? Num disisti daquilo, i sempri...

3. Mas que tipo de assistência seria essa? Assistência de alguém?

4. MP: Não, assistença assim da gente mesmo falá: i 'eu vô fazê aquilo, aquilo qui i' eu tenho vontade, né, de trabalhar pra... pra si consegui aquilo, a gente trabalha e consegue, o faiz aquilo que a gente tem vontade de fazê, né?

Vê-se que o informante não diz "precisa batalhá", "precisa lutá". O sucesso depende da insistência, da vontade, de trabalhar.

Portanto, mesmo que a metáfora SUCESSO É GUERRA de fato emerja do corpus da forma como Bronzato (2010) demonstra, o modelo cultural proposto não circunscreve um grupo ou grupos sociais específicos, ou, ainda, não se esclarece se é um modelo cultural genérico ou específico dadas certas situações e propósitos de comunicação. Por hipótese, SUCESSO seria relacionado com GUERRA, devido a um modelo cultural em que o sucesso é baseado em inserir-se numa competição. SUCESSO seria relacionado à DESTRUIÇÃO em contextos em que "fazer algo com maestria, por exemplo, CAUSA GRANDE IMPACTO A PARTIR DE UM CENTRO PARA VÁRIAS DIREÇÕES e, pela experiência humana, isso é o que ocorre de forma mais intensa em explosões, detonações, etc., em que "estruturas vêm abaixo".

Um exemplo de modelo cultural específico reconstruído a partir de corpora de entrevistas semiestruturadas transcritas, aplicação de escala Likert e de escala multi-item de valor modalidade (Cf. FELTES, 2018b), encontra-se na pesquisa de Pierozan (2019), sobre modelo cultural de gestão empresarial em uma empresa familiar. ${ }^{5}$ Damos destaque às entrevistas semiestruturadas, transcritas conforme a notação da Análise da Conversação. Realizaram-se 12 entrevistas com o corpo de gestores administrativos, separados em 4 grupos (G1: nível estratégico/direção; G2: nível estratégico/gerência; G3: nível tático/coordenação; e G4: nível operacional.). O objetivo aqui é demonstrar, de forma muito breve e sem detalhamentos, como o enquadre da interação e seus propósitos fazem emergir outros entendimentos de SUCESSO quando relacionados à relação dos indivíduos com os objetivos da empresa. No estágio de entrevistas individuais, não se está ainda na fase de tentar reconstruir o modelo cultural proeminente na respectiva empresa. O foco está na compreensão de cada fala, dando ênfase para conceitos, valores, proposições, metáforas, esquemas de imagens. De qualquer modo, a situação específica de interação com um grupo de sujeitos circunscritos por um propósito geral comum provavelmente gerará uma modelo de gestão em que SUCESSO não se baseie em destruição, guerra ou mera ascensão.

Por exemplo, o sujeito G2_S6 (grupo 2, sujeito 6) afirma

\footnotetext{
${ }^{5}$ Pierozan (2019) explora o design-metodológico para a reconstrução de modelos culturais que foi objeto de nosso projeto SEMACOG - MC II, a partir de um estudo exploratório de caso entre 2017-2019.
} 
183 um ambiente de trabalho muito bom, pelo menos onde eu consigo atuar 184 ou conviver com outras né:. as oportunidades vão vão surgir >se tu for atrás, se 185 desenvolver, tiver interesse, estudar < . a:: o salário inicialmente não vai ser o que tu vai 186 gostar provavelmente né:, como em qualquer, QUASE qualquer lugar, $\uparrow$ mas tendo essas 187 novas oportunidades, com certeza o reconhecimento vai vir. eu defino assim. é um local ...

O SUCESSO [NA EMPRESA] aqui se relaciona com PERSISTÊNCIA, INTERESSE, DESENVOLVIMENTO, VONTADE.

O sujeito G3_S9 afirma:

91então eu acho que, <nós sempre fomos> .hhh, como é que vou te explicar $\downarrow \uparrow$ os nossos clientes 92 eles, de uma maneira geral, sempre gostaram do nosso tipo de trabalhar, da nossa 93 sistemática porque nós sempre fomos flexíveis. que que é você ser flexível? você tem 94 que ter um preço condizendo com mercado, você tem que ter um prazo de entrega que 95 seja satisfatório, você tem que ter condições de pagamento que deixa o cliente 96 satisfeito dentro das tuas hhh das suas metas né:, então 个isso, no decorrer da história, nos fez 97 crescer muito. a flexibilidade da mg empreendimento perante o cliente, isso é uma 98 característica eu te diria marcante e importante, porque, a mg hoje é o terceiro 99 maior fabricante nacional de equipamentos na nossa linha. na nossa frente existem dois 100 gigantes no mercado. nós somos uma empresa .hhh de médio porte aqui::: no cantinho do do 101 do Brasil, quase que escondido do grande centro né: e $\uparrow$ mesmo assim, hoje, já fazem anos 102 nós somos o terceiro maior fabricante. como é que se consegue isso? <flexibilidade, 103 qualidade, trabalho, perseverança>, tudo isso nos ajudou a chegar nesse patamar

Outros elementos, nesse caso, repetem-se, PERSEVERANÇA, e outros são acrescentados: o sucesso da empresa baseou-se em SATISFAZER O CLIENTE, QUALIDADE e TRABALHO.

O sujeito G4_S11 afirma o que segue:

92 não. <eu desde quando eu comecei a entender a empresa ali sempre vi que>

93 eles buscam a qualquer custo aprimorar (.) o produto deles. sempre inovando e buscando 94 tecnologias novas, máquinas, .hhh modelos de redutores diferentes. não é uma coisa que 95 parou não s:abe, que nem você disse primeiro, não é a:: $\uparrow$ hoje temos fabricando isso aqui 96 e temos ganhando dinheiro e vamos vamos estacionar aqui._não, aqui não, aqui o negócio 97 anda, anda certamente

Ou seja, o SUCESSO DA EMPRESA baseia-se em APRIMORAMENTO e INOVAÇÃO. G4_S11, por sua vez, afirma em dois excertos aqui escolhidos:

203 eu acho que sim porque eles, eles $\uparrow$ meu deus $\downarrow$, eles pro trabalho, a empresa

204 deles aí eles levam acima de tudo né:.(.) eu vejo também uma coisa assi:m, eu pessoal, e

205 个 também, eu foco, > eu penso numa coisa que eu quero e busco e vou atrás<. eu até: já

206 comentei com várias pessoas > vou te dizer também<, que eu vejo que parece, me parece assim 207 que o empresário, tipo eles, parece que eles têm uma coisa a mais na::: porque eles vem, >vem 208 com umas ideias com uns assunto< um objetivo ali que: (.) às vezes nem te passou pela cabeça 209 mas eles FOCAM e ENXERGAM lá na frente né: .hhh e vai e dá certo

Nesses excertos, o SUCESSO EMPRESARIAL mantém-se ligado a APERFEIÇOAMENTO, FOCO, PERSISTÊNCIA, META. 
A Linguística Cognitiva trata de categorização e conceptualização por meio de diferentes modelos teóricos e diferentes metodologias. Minha escolha de pesquisa segue uma rota que cria uma interface muito forte com estudos em Antropologia Cognitiva. A noção de modelos cognitivos (idealizados) manteve-se atraente por um longo tempo, porque abarca muitas outras noções importantes (e.g. esquema de imagens, frames, radialidade, construções gramaticais, metáforas, metonímias).

O construto "modelo cultural" passou a ser mencionado em várias obras e artigos em Linguística Cognitiva. Por alguma razão, algumas vezes tem sido introduzido sem uma clara distinção com modelos cognitivos e, também, sem a menção à história desse construto na Antropologia Cognitiva, por exemplo, já que a pesquisa com modelos culturais (sempre relativa a culturas, subculturas, grupos e subgrupos sociais e, inclusive, a diferentes períodos históricos) segue procedimentos metodológicos com especificidades próprias. E, nesse contexto, a questão é a de como um modelo cultural pode ser identificado, "reconstruído", para que seja sustentada sua "existência", por meio de pesquisas empíricas.

Gatewood (2012) resume bem nosso ponto de vista no estágio em que nossa pesquisa se encontra:

\begin{abstract}
a antropologia tem afinidades de longa data tanto com a história quanto com a história natural. Essa perspectiva histórica torna os antropólogos muito céticos em relação às generalizações sobre toda a humanidade. Eles estão interessados em tais generalizações em toda a espécie, com certeza, mas cientes de que generalizações descobertas através de comparações de variações naturais podem se aplicar apenas a tipos particulares de sociedades, a tipos específicos de pessoas agindo em contextos específicos. (p. 363-364).
\end{abstract}

Nesse contexto, tornam-se importantes: componentes centrais amplamente compartilhados mas variáveis em relação a componentes periféricos ou variação meramente idiossincrática; padrões de compartilhamento entre indivíduos; diferenças culturais uniformes e amplamente compartilhadas, diferenças subculturais, graus de expertise, diversidade de perspectivas; como um dado tópico é objeto de discussão, entre outros fatores.

\title{
REFERÊNCIAS
}

BARSALOU, L.W. Situated simulation in the human conceptual system. Language and Cognitive Processes, v. 18, p. 513-562, 2003.

BARSALOU, L.W. Situated conceptualization. In: COHEN, Henri; LEFEBVRE, Claire (Eds.) Handbook of categorization in Cognitive Science. Amsterdam: Elsevier 2005. p 619-650.

BARSALOW, L. W. Grounded cognition: past, present, and future. Topics in Cognitive Science, v. $2, \mathrm{n}$. 4. p. 716-724, 2010.

BARTMIŃSKI, J. [ZINKEN, Jörg (Ed.)] Aspects of cognitive ethnolinguistics. London: Equinox, 2009. BORTONI-RICARDO, S. M. Problemas de comunicação interdialetal. Revista Tempo Brasileiro, n. 78/79, p. 9-32, 1984. 
BENNARDO, G.; MUNCK, V. C. Cultural models: genesis, methods, and experiences. New York: Oxford University Press, 2014.

BRONZATO, L. H. A abordagem sociocognitivista da construção de destransitivização: o enquadre da interdição. 2000. 115 fl. Dissertação (Mestrado em Letras: Lingüística) - Instituto de Ciências Humanas e Letras (ICHL), Universidade Federal de Juiz de Fora (UFJF), Juiz de Fora, 2000.

BRONZATO, L. H. O enquadre gramatical da interdição ou "a bom entendedor meia palavra basta". In: MIRANDA, N. S.; SALOMÃO, M. (Org.). Construções do Português do Brasil: da gramática ao discurso. Belo Horizonte: Ed. UFMG, 2009, p. 76-97.

BRONZATO, L. H. A construção gramatical de hiperbolização: um caso de coerência metafórica da gramática. 2010. 223fl. Tese (Doutorado em Letras) - Instituto de Letras, Universidade Federal Fluminense, Niterói, 2010.

COHEN, H.; LEFEBVRE, C. (Eds.) Categorization in Cognitive Science. New York: Elsevier, 2005. CROFT, W.; CRUSE, D. A. Cognitive linguistics. Cambridge: Cambridge University Press, 2006.

FELTES, H. P. M. Semântica Cognitiva: ilhas, pontes e teias. Porto Alegre: Edipucrs, 2007.

FELTES, H. P. M. Modelos culturais: teoria, estudos e métodos. Linguagem em (Dis)Curso (Online), v. 18, p. 193-213, 2018a.

FELTES, H. P. M. Modelos culturais e valores culturais: valor-modalidade. In: TENUTA A. M.; COELHO, S. M. (Org.). Uma abordagem cognitiva da linguagem: perspectivas teóricas e descritivas. Belo Horizonte: FALE/UFMG, 2018b. p. 47-76.

FILLMORE, C. J. Frames and the semantics of understanding. Quaderni di semantica, n. 6, p. 222-254, 1985.

FILLMORE, C. J. An alternative to checklist theories of meaning. In: COGEN C.; THOMPSON, H.; THURGOOD, G.; WHISTLER, K. (Eds.). Proceedings of the First Annual Meeting of the Berkeley Linguistics Society. Berkeley, 1975. p. 23-131.

GATEWOOD, J. B. Cultural models, consensus analysis, and the social organization of knowledge . Topics in Cognitive Science, v. 4, n. 3, p. 362-371, 2012.

GEERAERTS, D.; CUYCKENS, H. (Eds.) The Oxford handbook of Cognitive Linguistics. New York: Oxford University Press, 2007.

GIBBS, R. W. Embodiment and cognitive science. New York: Cambridge University Press, 2006.

HAIMOVICI, S. The modal-amodal distinction in the debate on conceptual format. Philosophies, v.3, n.7, p.1-13, 2018.

HARDER, P. Partial autonomy: ontology and methodology in cognitive linguistics. In: JANSSEN, T.; REDEKER, G. (Eds.). Cognitive Linguistics: foundations, scope, and methodology. New York: Mouton de Gruyter, 1999. p. 195-222.

HARDER, P. Meaning in mind and society a functional contribution to the social turn in Cognitive Linguistics. De Gruyter Mouton Berlin/New York. 2010.

HOLLAND, D.; QUINN, N. (Ed.) Cultural models in language and thought. Cambridge: Cambridge University Press, 1987.

KRISTIANSEN, G.; DRIVEN, R. (Eds.) Cognitive Sociolinguistics. New York: Mouton de Gruyter, 2008.

KÖVECSES, Z. Metaphor in culture: universality and variation. Cambridge: Cambridge University Press, 2005.

KÖVECSES, Z. Metaphor and emotion: language, culture, and body in human

feeling. Cambridge: Cambridge University Press, 2004.

LAKOFF, G. Women, fire, and dangerous things: what categories reveal about the mind. Chicago: The University of Chicago Press, 1987.

LAKOFF G.; JOHNSON, M. Philosophy in the flesh: the embodied mind and its challenge to Western thought. New York: Basic Books, 1999.

LAKOFF G.; KÖVECSES, Z. The cognitive model of anger inherent in American English. In: HOLLAND, D.; QUINN, N. (Ed.) Cultural models in language and thought. Cambridge: Cambridge University Press, 1987. p. 195-221. 
PIEROZAN, S. M. Modelos culturais de gestão empresarial: um estudo com valores-modalidade na interface entre Linguística Cognitiva e Antropologia cognitiva. 2010. 295 fl. Tese (Doutorado em Letras) - Centro de Humanidades, Universidade de Caxias do Sul/ UniRitter, Caxias do Sul, 2019.

QUINN, N. Convergent evidence for a cultural model of American marriage. In: HOLLAND, D.; QUINN, N. (Eds.) Cultural models in language and thought. Cambridge: Cambridge University Press, 1987. p. 173-192.

QUINN, N. The cultural basis of metaphor. In: FERNANDEZ, J. (Ed.) Beyond metaphor: the theory of tropes in Anthropology. Stanford, California: Stanford University Press, 1991. p. 56-93.

SALOMÃO, M. M. M. FrameNet Brasil: um trabalho em progresso. Calidoscópico, v. 7, n. 3, p. 171$182,2009$.

SHAPIRO, L. Embodied cognition. New York: Routledge, 2011.

SINHA, C. Grounding, mapping, and acts of meaning. In: JANSSEN, T.; REDEKER, G. (Ed.) Cognitive linguistics: foundations, scope, and methodology. New York: Mouton de Gruyter, 1999. p. 223-255.

SMITH, E. E.; MEDIN, D. L. Categories and concepts. Cambridge Mass.: Harvard University Press, 1981.

TAYLOR, J. R. Linguistic categorization. 3rd. ed. New York: Oxford University Press, [1989] 1995.

UNGERER, F.; SCHMID, H-J. An introduction to Cognitive Linguistics. 2nd ed., Harlow:

Pearson/Longman, 2006.

YUANQIONG, W. On the relationship between metaphor and cultural models - with data from Chinese and English language. Metaphorik.de, n. 17, p. 115-134, 2009.

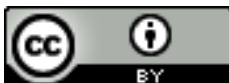

Este texto está licenciado com uma Licença Creative Commons Atribuição 4.0 Internacional. 